- COMMENTARY

Volume 10 Issue 22018

DOI: 10.21315/eimj2018.10.2.6

ARTICLE INFO

Submitted: 28-02-2018

Accepted: 29-05-2018

Online: 29-06-2018

\section{Utilising the Curriculum Committee to Strengthen Teaching-Learning in a Medical School}

\author{
P Ravi Shankar', Gabriel Dakubo² \\ ${ }^{1}$ Department of Medical Education, American International Medical \\ University, Gros Islet, SAINT LUCIA \\ ${ }^{2}$ Department of Microbiology, American International Medical \\ University, Gros Islet, SAINT LUCIA
}

To cite this article: Shankar PR, Dakubo G. Utilising the curriculum committee to strengthen teaching-learning in a medical school. Education in Medicine Journal. 2018;10(2):49-54. https://doi. org/10.21315/eimj2018.10.2.6

To link to this article: https://doi.org/10.21315/eimj2018.10.2.6

\begin{abstract}
The article examines various initiatives undertaken by the curriculum committee at an offshore Caribbean medical school to strengthen teaching-learning. The authors examined various initiatives undertaken by the committee since September 2017. They also searched the scientific literature for brief descriptions of similar initiatives at other medical schools in the Caribbean and other regions. A number of initiatives have been introduced to strengthen the curriculum and teaching-learning. Among the new initiatives were creating a structured outline for course syllabi, initiating online modules on nutrition in medicine and patient safety, introducing a health humanities module, starting a module on integrative medicine, system-wise sequencing of the fourth semester, conducting sessions on critical appraisal of scientific literature, and introducing a day long orientation programme. The impact of these initiatives can be assessed in the future.
\end{abstract}

Keywords: Caribbean, Curriculum committee, Medical schools, Teaching-learning International Medical University, AIM-U Ave, Beausejour Road, North Entrance, Gros Islet, Saint Lucia | E-mail: ravi.dr.shankar@gmail.com

\section{INTRODUCTION}

Offshore Caribbean medical schools (OCMS) admit students mainly from the United States (US), Canada, India, Nigeria, Ghana and other countries to the undergraduate medical (MD) course. Students complete the basic sciences in the Caribbean and do their clinical rotations in the US, Canada or major Caribbean hospitals (1). OCMS have autonomy with regard to the courses offered, instructional methods used, and subjects covered to prepare students for various licensing examinations including the United States Medical Licensing Examination (USMLE). USMLE content outlines, content outlines from US and Canadian medical schools, and guidelines from the regional and other accrediting agencies are considered while determining the curriculum at these schools. Many OCMS have three student intakes a year, in January, May, and September. The total duration of the course of study is four years. 


\section{THE ROLE OF THE CURRICULUM COMMITTEE}

The curriculum committee (CC) plays an important role in monitoring and strengthening teaching-learning at OCMS. Assessment drives learning and in many institutions the CC is also in charge of assessment while other schools have a separate examination committee. The CC has a tremendous responsibility with regard to student learning, having overall responsibility for both the basic sciences and clinical rotations. The CC has faculty members from the basic sciences and clinical faculty. The committee also has student members from both the basic and clinical sciences who are usually selected for

Table 1: Curricular modifications at the institution since September 2017

\begin{tabular}{ll}
\hline Course module & Semester offered \\
\hline Course syllabi & $\begin{array}{l}\text { All basic science and } \\
\text { clinical semesters }\end{array}$ \\
& \\
$\begin{array}{l}\text { Healthcare quality } \\
\text { improvement }\end{array}$ & $\begin{array}{l}\text { MD1 and sequentially } \\
\text { to other semesters }\end{array}$ \\
& \\
$\begin{array}{l}\text { Critical appraisal of } \\
\text { scientific literature }\end{array}$ & $\begin{array}{l}\text { MD1 and sequentially } \\
\text { to other semesters }\end{array}$
\end{tabular}

\section{Brief description}

All course syllabi should specify the course objectives, linkage of the course and the programme objectives, and provide specific learning objectives for each session. Small group and practical learning sessions should be described. Reading and writing assignments should be mentioned.

This online module introduces students to healthcare quality, patient safety, and leadership.

The MD1 students will continue taking this course as they progress to higher semesters. Students will get a certificate at the completion of the course.

This module introduces students to critical analysis of research, clinical trials, meta-analysis and systematic reviews. The MD1 students will continue taking sections of this course as they progress during MD2, 3, and 4.

Health humanities $\quad$ MD2

Clinical rotations Clinical semesters

Nutrition in

MD2

medicine

MD4

Integrative

medicine

System-wise

MD4 sequencing of subjects
The small group activity-based module explores important issues in health education through the use of the humanities.

The course syllabus has been modified. There is a closer linkage of rotation objectives with the programme objectives. Specific areas of study and diseases are mentioned and importance is given to clinical assessment and assessment during the rotations by the preceptor and others.

This online module from the University of North Carolina introduces students to nutrition and will build on the concepts offered during the prehealth course.

Students review topics like yoga, meditation, mindbody medicine, herbal and botanical medicine using online courses followed by discussions with their course coordinator.

The subjects of Pathology, Physical diagnosis, and Pharmacology are learned as organ systems. Students pass an integrated exam at the end of each organ system and a comprehensive exam at the end of the semester. 
a trimester. The criteria for selecting student members are interest, motivation, ability to contribute to the deliberations, readiness to represent student interests, and good academic standing.

\section{AUTHORS' EXPERIENCE WITH CURRICULUM COMMITTEE}

The authors have been involved with the CC at two OCMS. A higher degree in health professions education is useful for members of the CC. The American International Medical University (AIMU) in Saint Lucia offers undergraduate courses in both medicine and nursing. The CC at AIMU embarked on the task of further strengthening teaching-learning and maintaining proper documentation of meetings. Faculty development activities are important to equip faculty members to be effective learning facilitators. The authors have facilitated sessions on learning objectives, self-directed learning, and lesson planning. Table 1 shows the various curricular changes at the institution since September 2017.

\section{COURSE SYLLABUS AND ONLINE MODULES}

The CC rewrote the MD program objectives from the student perspective. The subject syllabi were also modified to include learning objectives for each subject and session, and to highlight the linkage between the subject and programme objectives. In addition to the cognitive domain, the psychomotor and affective domains were also emphasised. Faculties are also required to specify which topics and/or activities during the course address the skills of critical analysis and judgement, and self-directed learning. The Caribbean Accreditation Authority for Education in Medicine and other Health Professions
(CAAM-HP) is the accrediting body for Saint Lucia and the revised standards of the agency emphasise self-directed learning and critical analysis and judgement among other skills (2). Faculties are also required to provide reading and writing assignments for students.

Nutrition is becoming increasingly important to preserve health and treat disease. The biochemical aspects of nutrition are emphasised during medical school, but diet and dietary modifications have been stressed less. The University of North Carolina in the US offers an online nutrition in medicine module (www.nutritioninmedicine.org). This is an important resource for medical and health students (3). From September 2017, we are offering this module to our second trimester students. The US Institute for Healthcare Improvement (www.ihi.org) offers online modules on the subjects of healthcare quality, leadership, and patient safety. From September 2017, we are offering first trimester students certain topics of this module. They will complete other topics as they progress through the second and third trimester.

\section{BEHAVIOURAL AND SOCIAL SCIENCES}

The behavioural sciences and medical ethics are important for medical practice. The CC with the help of a clinical psychologist modified the teaching-learning of these subjects to include more practical aspects and small group activities. Health humanities $(\mathrm{HH})$ use subjects traditionally known as the humanities for specific purposes in health science education. A HH module is offered to the second trimester medical and first semester bachelor of nursing students using small group, active learning strategies, and provides opportunities for interprofessional learning. 


\section{TEACHING-LEARNING DURING THE CLINICAL ROTATIONS}

The CC has student members completing their clinical rotations in the US who join the meetings electronically and provides inputs about clinical teaching-learning. There is also a student member who is doing his rotations at Jamaica. The CC with other school committees is working on strengthening clinical learning and ensuring uniformity of clinical experiences across various sites. A modified framework for teaching-learning and assessment is being implemented, and the subject syllabi for the core rotations are being strengthened. The overall duration of the core rotations are being extended by 10 weeks.

\section{INTEGRATIVE MEDICINE}

Complementary and alternative therapies are being increasingly used by patients all over the world requiring these topics to be included in medical education (4). Integrative medicine emphasises healing, the relationship between the patient and the physician, and utilises both complementary remedies and conventional allopathic medicine (5). The brief online module being offered for fourth semester students addresses yoga, spirituality, botanical and herbal remedies, and mind-body medicine among others. Students discuss these topics further with their course coordinator. We plan to develop this module further in future.

\section{SYSTEM-WISE SEQUENCING OF THE MD4 SEMESTER}

Nearly all medical schools in North America and many in the Caribbean follow an integrated organ system-based approach to learning the basic sciences. Shifting from a subject-based to an integrated curriculum is challenging. In a medical school in Aruba, faculty apprehensions about the integrated curriculum, concerns about self-directed learning and early clinical exposure were among the challenges faced (6). The curriculum committee can play an important role in discussing these challenges, developing an action plan and reducing apprehensions. AIMU follows a subject-based curriculum. During the fourth semester, the subjects of Pathology, Physical Diagnosis, and Pharmacology are addressed. From January 2018, these subjects have been sequenced together as organ systems. Basic concepts, peripheral nervous system, cardiovascular system, musculoskeletal system, respiratory system, haematopoietic system, gastrointestinal system, renal system, central nervous system, and endocrine and reproductive system are among the systems covered. The CC is considering whether the subjects of Anatomy, Physiology, and Histology can be learned using an integrated system-based approach during the first or second trimester. The school is also examining the possibility of shifting to a fully integrated curriculum for the basic sciences.

\section{CRITICAL APPRAISAL OF SCIENTIFIC LITERATURE}

Medical students must learn how to critically appraise the scientific literature and practice evidence-based medicine (7). They should know about the interpretation of published original research, randomised clinical trials, systematic reviews, and metaanalysis. Critical appraisal was introduced as an activity-based session for the first semester students in September 2017. During the first two semesters, students learn about the critical appraisal of original research and randomised trials. During the third and fourth semesters, they learn about critically evaluating systematic reviews and meta-analysis. These sessions are being sequentially introduced at the institution.

\section{ORIENTATION PROGRAMME}

At the beginning of medical school, students should be properly oriented to the school, 
the area where the school is located, the curriculum, the assessment methods, sources of student support, student safety, and financial counseling among other issues. The sessions can serve to introduce students to each other and promote their working together as team. Student knowledge about various issues increased significantly after an orientation programme in a medical school (8). Table 2 provides details about the various sessions conducted during the recent orientation day at the institution.

Table 2: Topics addressed during the recent orientation programme

\begin{tabular}{l}
\hline Topic \\
\hline Introduction to AIMU \\
Overview of various academic programmes \\
offered at AIMU \\
MD program at AIMU \\
Why you should care about accreditation \\
Student services at AIMU \\
Campus services at AIMU \\
Student life \\
Living in St Lucia \\
Fire and life safety education \\
Being responsible for your own safety \\
Office of the Registrar \\
Career counseling \\
Personal counseling \\
The AIMU Library \\
Research at AIMU \\
Financial counseling \\
Early clinical exposure \\
Student organisations
\end{tabular}

The CC makes and ratifies decisions by consensus among its members. The CC at AIMU is presently working on early clinical exposure, developing standardised patients and strengthening clinical learning during the basic sciences. The CC is aware that including new modules in the curriculum will increase student workload.
The CC plans to request faculty members to re-examine their courses to remove less relevant material. Joint sessions will also be conducted where faculties can remove redundancies in various subjects/courses. The CC will continue to work on various aspects of the curriculum and teachinglearning to create better doctors.

\section{CONCLUSION}

The CC provides a forum for faculty members and the student representatives to introduce new modules and courses and to strengthen teaching-learning. CC exists in most OCMS and can be strengthened with the inclusion of health professions educators and student representation to strengthen teaching-learning.

\section{LESSON LEARNT}

The CC is an important committee in an OCMS with members from the faculty, health educators and students and serves as an important forum to discuss and implement curricular changes and innovations. CC ensures faculty and student input in curricular decisions and improves the likelihood of the changes being accepted by them.

\section{REFERENCES}

1. Eckhert NL. Private schools of the Caribbean: outsourcing medical education. Acad Med. 2010;85:622-30. https://doi. org/10.1097/ACM.0b013e3181d2aee1

2. Caribbean Accreditation Authority for Education in Medicine and other Health Professions. Revised standards for the accreditation of medical schools in the Caribbean community, 2017. [cited 2018 May 20]. Available from: http://www.caamhp.org/documents.html 
3. Shankar PR. An online nutrition in medicine module: an important resource for medical students and physicians. Educ Health. 2015;28:109-10. https://doi. org/10.4103/1357-6283.161954

4. Wetzel MS, Kaptchuk TJ, Haramati A, Eisenberg DM. Complementary and alternative medical therapies: implications for medical education. Ann Int Med. 2003;38:191-6. https://doi. org/10.7326/0003-4819-138-3-20030204000011

5. Maizes V, Schneider C, Bell I, Weil A. Integrative medical education: development and implementation of a comprehensive curriculum at the University of Arizona. Acad Med. 2002;77:8851-60. https://doi. org/10.1097/00001888-200209000-00003
6. Shankar PR. Challenges in implementing an integrated curriculum in a Caribbean medical school. Education in Medicine Journal. 2014;6(4):74-7. https://doi. org/10.5959/eimj.v6i4.290

7. Inam SNB. Experience of teaching critical appraisal of scientific literature to undergraduate and postgraduate students at the Ziauddin Medical University, Karachi, Pakistan. Int J Health Sci (Qassim). 2007;1:119-24.

8. Shankar PR, Dwivedi NR, Balasubramanium R, Dakubo GD. Student knowledge and perception before and after an orientation program in an offshore Caribbean medical school. Education in Medicine Journal. 2015;7(1):57-63. https:// doi.org/10.5959/eimj.v7i1.317 